\title{
In vivo anti-hyperlipidemic activity of the triterpene from the stem bark of Protorhus longifolia (Benrh) Engl
}

\author{
Kgothatso E Machaba', Sinazo ZZ Cobongela', Rebamang A Mosa', Lawal A Oladipupo², Trayana G Djarova
} and Andy R Opoku"

\begin{abstract}
Background: Hyperlipidemia, a metabolic disorder of lipids, is a well known risk factor of cardiovascular events and metabolic syndrome. In this study, the in vivo lipid-lowering activity of the triterpene (Methyl-3ß-hydroxylanosta-9, 24-dien-21-oate), isolated from the stem bark of Protorhus longifolia, in high fat diet (HFD)-induced hyperlipidemic rats was investigated.

Methods: Structure of the isolated compound was established and confirmed based on spectral (NMR, HRMS, IR) data analysis. Rats were divided into two groups; normal group (fed the normal commercial rats' chow) and the HFD group. After 21 days of experimental period on their respective diets, the HFD rats were sub-divided into 4 groups of six rats per group. Two of the HFD groups were orally treated with the triterpene (100 and $200 \mathrm{mg} / \mathrm{kg}$ body weight) for 15 days. At the end of the experimental periods, the rats were sacrificed and blood samples were collected for biochemical assays.

Results: The results show that there were significant increases in total serum cholesterol (TC, $15.72 \mathrm{mmol} / \mathrm{L})$ and low-density lipoprotein cholesterol $(\mathrm{LDL}-\mathrm{C}, 7.41 \mathrm{mmol} / \mathrm{L})$ with a reduction in high-density lipoprotein cholesterol (HDL-c, $14.75 \mathrm{mmol} / \mathrm{L}$ ) in HFD-induced hyperlipidemic rats after 21 days. Oral administration of the triterpene $(100 \mathrm{mg} /$ kg.bw and $200 \mathrm{mg} / \mathrm{kgg.bw})$ for a period of 15 days resulted in significant lowering of the levels of TC $(7.51 \mathrm{mmol} / \mathrm{L})$ and LDL-c ( $4.46 \mathrm{mmol} / \mathrm{L})$ with an increase in HDL-c $(47.3 \mathrm{mmol} / \mathrm{L})$ in HFD-induced hyperlipidemic rats. Significant decrease in atherogenic index and coronary risk index by the triterpene was observed in HFD-induced hyperlipidemic rats.
\end{abstract}

Conclusions: The triterpene could effectively reduce or control the amount of serum cholesterol and LDL. It is apparent that the compound could contribute to new formulation with significant hypolipidemic effects.

Keywords: Hyperlipidemia, High fat diet, Triterpene

\section{Background}

Hyperlipidemia, a disorder of lipid metabolism characterized by elevated levels of lipids circulating in the blood, has now become a global concern. It is considered as one of the five leading causes of death in the world [1]. Its prevalence is greatly influenced by adaptation of sedentary lifestyle and an increase in consumption of a high-fat diet [2]. Hyperlipidemia is strongly linked to the development of cardiovascular events and metabolic syndrome diseases

\footnotetext{
* Correspondence: OpokuA@unizulu.ac.za

${ }^{1}$ Department of Biochemistry and Microbiology, University of Zululand, Private Bag X1001, KwaDlangezwa 3886, Republic of South Africa Full list of author information is available at the end of the article
}

[3]. Thus, regulation of blood lipid levels is vital in the prevention and treatment of hyperlipidemia and its related diseases.

Currently, a number of anti-hyperlipidemic agents have been introduced for the treatment of hyperlipidemia. One of the most widely used anti-hyperlipidemic agents at present is lovastatin, which reportedly slows down the body's ability to make cholesterol by targeting hepatocytes and inhibiting HMG-CoA reductase; the enzyme that converts HMG-CoA into mevalonic acid, a cholesterol precursor [4]. However, this drug is associated with undesirable side effects (such as myositis and rhabdomyolysis, elevated CK levels, muscle weakness, 
and muscle cramps) in humans [5,6]. Such adverse effects of the current anti-hyperlipidemic drugs stimulate the search for alternative medicine with improved efficacy and safety profile.

Medicinal plants have always been rich sources of biologically active compounds vital to human health. Thus a search for new lead molecules with anti-hyperlipidemic properties from plants could be a useful strategy. Antihyperlipidemic activity of a number of medicinal plants and/or plant-derived bioactive compounds has been reported. Such studies include the hypolipidemic activity of Pandanus tectorius fruit extract [7], Coriolus versicolor [6] and 2, 4, 6-Trihydroxyacetophenone isolated from Myrciamultiflora [8].

Stem bark of Protorhus longifolia (Benrh.) Engl. (Anacardiaceae), a tree indigenous to Southern Africa, is one of the plants commonly used by Zulu traditional healers in the management of blood-clotting related diseases. Antimicrobial activity of the leaf extracts of the plant has been reported [9]. Cytotoxic and anti-platelet aggregation activity of the crude extracts and two lanosteryl triterpenes from the stem bark of the plant have recently been reported [10,11]. A growing body of evidence support plant-derived triterpenes as new targets for drug development due to their diverse potential pharmacological activities. The in vitro anti-hyperlipidemic activity of methyl-3 $\beta$-hydroxylanosta-9,24-dien-21-oate isolated from Protorhus longifolia has been observed in our laboratory (unpublished data). The present study reports on the in vivo hypolipidemic activity of the triterpene from Protorhus longifolia in a high fat diet (HFD)-induced hyperlipidemia in rats.

\section{Results}

The structure of the isolated compound (Figure 1) was established and confirmed using ${ }^{1} \mathrm{H}$ and ${ }^{13} \mathrm{C}-\mathrm{NMR}$. The isolated compound (Methyl-3 $\beta$-hydroxylanosta-9,24-dien21-oate, KE1) was obtained as white crystals, > 95\% pure, $\mathrm{mp} 204-205^{\circ} \mathrm{C}$, IR (KBr) $v_{\max }=3469,1683 \mathrm{~cm}^{-1}$. See

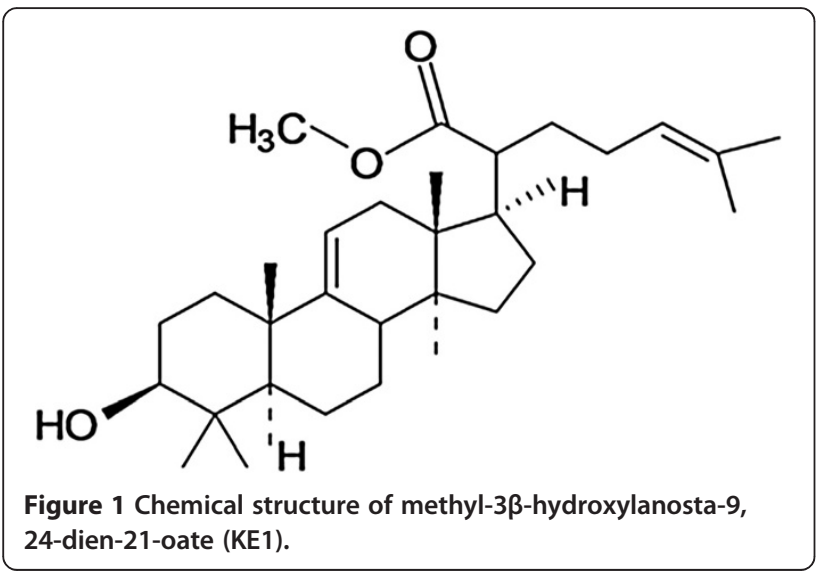

Table 1 for ${ }^{1} \mathrm{H}$ and ${ }^{13} \mathrm{C}$ NMR data. The data suggested the molecular formula $\mathrm{C}_{31} \mathrm{H}_{50} \mathrm{O}_{3}$, calculated 470.736. Spectra of the compound are presented in Additional file 1.

The effects of the normal diet (ND) and HFD fortified with different concentrations of KE1 or lovastatin on the body weight, food conversion, food efficiency ratio, liver weights and adiposity level in HFD fed rats over the period of study are shown in Table 2 . The control group of rats subjected to ND for 21 and 36 days showed significant increase $(\mathrm{p}<0.05)$ in the body weight by $12.12 \%$ and $41.93 \%$, respectively. It is apparent that the rats were gaining weight over the 36 days of study. The control group of rats subjected to HFD for 36 days showed an

Table $1{ }^{13} \mathrm{C}-\mathrm{NMR}$ data and significant ${ }^{1} \mathrm{H}-\mathrm{NMR}$ data of the compound

\begin{tabular}{|c|c|c|c|}
\hline Position & $\delta_{C}(p p m)$ & Type & $\delta_{H}(p p m)$ \\
\hline 1 & 30.4 & $\mathrm{CH}_{2}$ & \\
\hline 2 & 23.9 & $\mathrm{CH}_{2}$ & \\
\hline 3 & 74.3 & $\mathrm{CH}$ & $4.25(1 \mathrm{H}, \mathrm{s}, \mathrm{OH})$ \\
\hline 4 & 37.4 & C & \\
\hline 5 & 44.4 & $\mathrm{CH}$ & \\
\hline 6 & 17.3 & $\mathrm{CH}_{2}$ & \\
\hline 7 & 25.8 & $\mathrm{CH}_{2}$ & \\
\hline 8 & 49.6 & $\mathrm{CH}$ & \\
\hline 9 & 145.9 & C & \\
\hline 10 & 34.7 & C & \\
\hline 11 & 118.3 & $\mathrm{CH}$ & $5.11(1 \mathrm{H}, \mathrm{t})$ \\
\hline 12 & 28.6 & $\mathrm{CH}_{2}$ & \\
\hline 13 & 43.3 & C & \\
\hline 14 & 51.0 & C & \\
\hline 15 & 31.3 & $\mathrm{CH}_{2}$ & \\
\hline 16 & 27.0 & $\mathrm{CH}_{2}$ & \\
\hline 17 & 47.7 & $\mathrm{CH}$ & \\
\hline 18 & 13.3 & $\mathrm{CH}_{3}$ & \\
\hline 19 & 21.7 & $\mathrm{CH}_{3}$ & \\
\hline 20 & 48.4 & $\mathrm{CH}$ & \\
\hline 21 & 177.3 & C & \\
\hline 22 & 34.7 & $\mathrm{CH}_{2}$ & \\
\hline 23 & 25.5 & $\mathrm{CH}_{2}$ & \\
\hline 24 & 125.6 & $\mathrm{CH}$ & $5.21(1 \mathrm{H}, \mathrm{t})$ \\
\hline 25 & 136.4 & $C$ & \\
\hline 26 & 17.4 & $\mathrm{CH}_{3}$ & $1.61(3 \mathrm{H}, \mathrm{s})$ \\
\hline 27 & 25.8 & $\mathrm{CH}_{3}$ & $1.65(3 \mathrm{H}, \mathrm{s})$ \\
\hline 28 & 21.9 & $\mathrm{CH}_{3}$ & $1.21(3 \mathrm{H}, \mathrm{s})$ \\
\hline 29 & 27.4 & $\mathrm{CH}_{3}$ & $0.90(3 \mathrm{H}, \mathrm{s})$ \\
\hline 30 & 22.1 & $\mathrm{CH}_{3}$ & $1.16(3 \mathrm{H}, \mathrm{s})$ \\
\hline$-\mathrm{OCH}_{3}$ & 59.8 & & $3.85(3 \mathrm{H}, \mathrm{s})$ \\
\hline
\end{tabular}

${ }^{13}$ C-NMR- carbon-13 NMR, 1H-NMR- Hydrogen-1(proton) NMR. 
Table 2 Effect of the triterpene on percentage weight change, food conversion, food efficiency ratio, liver weights and adiposity level in HFD rats

\begin{tabular}{llllll}
\hline Group & Weight change (\%) & Food Conversion & Food Efficiency Ratio & Liver (g) & Adiposity level $\times$ 10 \\
\hline ND (after 21 days) & $12.12 \pm 0.44^{* * *}$ & $0.82 \pm 0.07$ & $1.23 \pm 0.14^{* * *}$ & $3.37 \pm 0.17$ & $1.17 \pm 0.03$ \\
(after 36 days) & $41.93 \pm 6.29$ & $0.21 \pm 0.02$ & $4.91 \pm 0.47$ & $2.97 \pm 0.03$ & $1.17 \pm 0.04$ \\
HFD (after 21 days) & $6.18 \pm 1.09$ & $1.30 \pm 0.35$ & $0.96 \pm 0.25$ & $4.67 \pm 0.06$ & $1.02 \pm 0.01$ \\
(after 36 days) & $13.66 \pm 1.77^{* * *}$ & $0.62 \pm 0.05$ & $1.53 \pm 0.13^{* * *}$ & $5.21 \pm 0.29^{* * *}$ & $1.06 \pm 0.01^{*}$ \\
HFD/KE1 (100 mg/kg) & $6.01 \pm 1.57$ & $0.75 \pm 0.14$ & $1.12 \pm 0.40$ & $4.68 \pm 0.21$ & $1.04 \pm 0.01$ \\
HFD/KE1 (200 mg/kg) & $10.04 \pm 2.72$ & $0.19 \pm 0.02$ & $4.43 \pm 1.03^{* * *}$ & $5.73 \pm 0.18$ & $1.08 \pm 0.01$ \\
HFD/lovastatin (10 mg/kg) & $3.74 \pm 1.20^{* *}$ & $2.17 \pm 0.59^{* *}$ & $0.69 \pm 0.14$ & $4.75 \pm 0.14$ & $1.03 \pm 0.01$ \\
\hline
\end{tabular}

All values are expressed as mean \pm SEM, $(n=4)$; ${ }^{*} p<0.05$, **p $<0.01$, *** $p<0.001$ compared to the HFD 36 days.

${ }^{*} p<0.05,{ }^{* *} p<0.01,{ }^{* * *} p<0.001$ compared to the ND 36 days.

increase in body weight (13.66\%), food conversion and liver weight but a reduction in food efficiency ratio and adiposity level compared to control group of rats subjected to ND for 21 days. Like lovastatin, a standard hypolipidemic drug, treatment with the triterpene at $100 \mathrm{mg} / \mathrm{kg} . \mathrm{bw}$, according to HFD (after 36 days), indicated a potential reduction in percentage body weight, food efficiency ratio, liver weights, adiposity level and an increase in food conversion in rats.

Table 3 presents the results on the effects of the HFD and HFD fortified with different concentrations of KE1 and lovastatin on total cholesterol and triacylglyceride levels. The hyperlipidemia group of rats subjected to HFD for 21 and 36 days indicated an increase $(\mathrm{p}<0.001)$ in total cholesterol and LDL with increases in HDL levels. A statistically significant reduction $(\mathrm{p}<0.001)$ in total cholesterol and LDL accompanied by a significant increase in HDL was observed in the animals fed the HFD fortified with the triterpene at 100 and $200 \mathrm{mg} / \mathrm{kg}$. bw according to HFD (after 36 days). There were no statistically significant changes observed in triacylglyceride and VLDL levels compared to normal group of rats fed ND for 36 days.

The effect of the triterpene on atherogenic index and coronary risk index in hyperlipidemic rats was also evaluated and the results are given in Figure 2. The triterpene at different concentrations (100 and $200 \mathrm{mg} / \mathrm{kg} . \mathrm{bw})$ exhibited a significant reduction in atherogenic index and coronary risk index in HFD-induced hyperlipidemic animals for 36 days. Similar results were also observed in the rats fed HFD fortified with lovastatin.

The results for liver enzymes (ALP, ALT and AST) levels along with histopathological changes of the rat liver following treatment with HFD fortified with the triterpene are presented in Table 4 and Figure 3, respectively. Reduced levels of the liver enzymes were observed in rats treated with HFD fortified with the triterpene reaching levels similar to those in the ND group. Liver tissue from the rat treated with the triterpene depicted a lower accumulation of lipid droplets as compared to the liver of the rat fed HFD only in which numerous fat droplets and severe vascular changes with displaced nuclei were evident.

\section{Discussion}

The structure of the isolated compound (Figure 1) was established and confirmed on the basis of ${ }^{1} \mathrm{H}$ and ${ }^{13} \mathrm{C}$ NMR data analysis. The ${ }^{1} \mathrm{H}-\mathrm{NMR}$ of the compound followed the same triterpenoid pattern observed in $3 \beta$ hydroxylanosta-9,24-dien-21-oic acid [11], with a large clusters of signals of $\mathrm{CH}_{3}, \mathrm{CH}_{2}$ and $\mathrm{CH}$ between $\delta_{\mathrm{H}} 2.5$ and 0.8 . The ${ }^{13} \mathrm{C}-\mathrm{NMR}$ of this compound also resembled that of 3ß-hydroxylanosta-9,24-dien-21-oic acid, with five quaternary carbon atoms, and the presence of four olefinic carbon atoms between 145-118 ppm confirming the lanosteryl skeletal structure. The presence of an ester

Table 3 Effect of the triterpene on serum lipids and lipoproteins levels (mmol/L) in HFD-induced hyperlipidemia in rats

\begin{tabular}{llllll}
\hline Group & Total cholesterol & Triglyceride & VLDL-c & LDL-c & HDL-c \\
\hline ND (after 21 days) & $1.38 \pm 0.12$ & $0.68 \pm 0.11$ & $0.14 \pm 0.04$ & $0.11 \pm 0.04$ & $1.14 \pm 0.90$ \\
(after 36 days) & $1.83 \pm 0.24$ & $0.79 \pm 0.06$ & $0.26 \pm 0.18$ & $0.10 \pm 0.02$ & $1.86 \pm 0.07$ \\
HFD (after 21 days) & $15.72 \pm 1.10$ & $1.29 \pm 0.54$ & $0.28 \pm 0.22$ & $7.41 \pm 0.56^{* *}$ & $14.75 \pm 0.19^{* * *}$ \\
(after 36 days) & $49.52 \pm 4.83^{* * *}$ & $1.41 \pm 0.35$ & $0.28 \pm 0.14$ & $10.72 \pm 0.94^{* * *}$ & $6.17 \pm 0.16^{* * *}$ \\
HFD/KE1 (100 mg/kg) & $34.24 \pm 1.50^{* * *}$ & $1.93 \pm 0.15$ & $0.39 \pm 0.05$ & $5.85 \pm 0.81^{* * *}$ & $30.39 \pm 0.92^{* * *}$ \\
HFD/KE1 (200 mg/kg) & $7.51 \pm 0.97^{* * *}$ & $0.46 \pm 0.05$ & $0.09 \pm 0.01$ & $4.46 \pm 0.82^{* * *}$ & $47.30 \pm 0.9^{* * *}$ \\
HFD/lovastatin $(10 \mathrm{mg} / \mathrm{kg})$ & $38.66 \pm 3.25^{*}$ & $0.77 \pm 0.13$ & $0.15 \pm 0.03$ & $12.97 \pm 0.59$ & $29.13 \pm 0.68^{* * *}$ \\
\hline
\end{tabular}




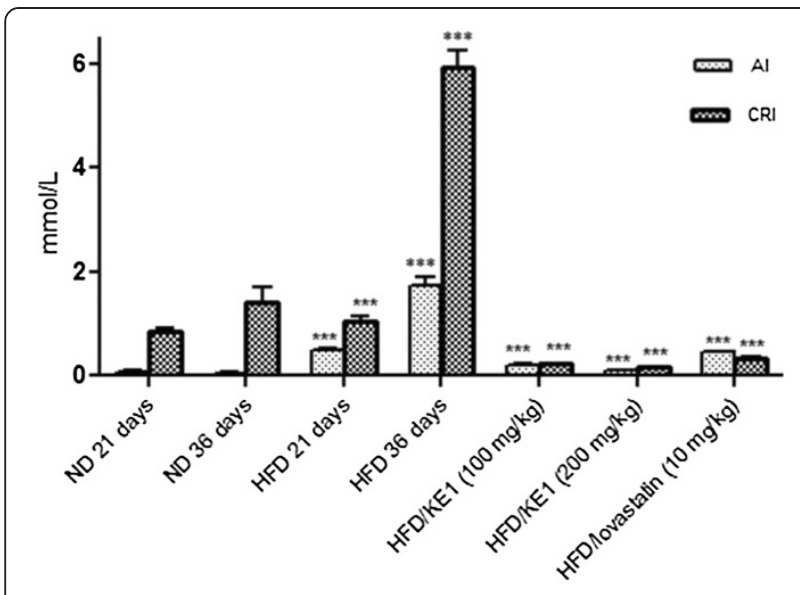

Figure 2 Effect of the triterpene on atherogenic index (AI) and coronary risk index (CRI) in HFD-induced hyperlipidemia in rats. All values are expressed as mean \pm SEM, $(n=4)$; *** $p<0.001$ compared to the HFD 36 days; ${ }^{* * *} \mathrm{p}<0.001$ compared to the ND 36 days.

carbon atom at $\delta_{\mathrm{C}} 177.3$ instead of a carboxylic carbon at $\delta_{\mathrm{C}} 181.5$ assisted in suggesting the methyl ester of $3 \beta$ hydroxylanosta-9,24-dien-21-oic acid. Detailed assignment of the ${ }^{13} \mathrm{C}$-NMR and significant ${ }^{1} \mathrm{H}$-NMR of the compound are presented in Table 1 . The absorption bands for carbonyl $\left(1683 \mathrm{~cm}^{-1}\right)$, and hydroxyl $\left(3469 \mathrm{~cm}^{-1}\right)$ functional groups observed on IR spectrum also further assisted in confirming the NMR structure.

Consumption of a high-lipid diet may create diverse patterns of hyperlipidemia. Abnormalities of lipid metabolism are associated with cardiac diseases, obesity and their associated disorders [12]. Thus regulation of dyslipidemia is crucial for the prevention and treatment of cardiovascular events $[13,14]$.

In this study, the hypolipidemic activity of the triterpene from stem bark of $P$. longifolia was evaluated in the HFD-induced hyperlipidemia in rats. The results obtained from this study demonstrate that the triterpene has anti-hyperlipidemic properties. The ability of the HFD supplemented with the triterpene to significantly $(\mathrm{p}<0.001)$ lower serum TC and LDL-c levels while increasing HDL-c levels (Table 3) suggested the hypolipidemic activity of the compound. These results are consistent with other literature reports on the hypolipidemic activity of plant-derived compounds. A triterpenoid mixture ( $\alpha, \beta$-amyrin) from Protium heptaphyllum [15] and lanostane triterpenoids from Prosthechea michuacana [16] have been reported to exert their hypolipidemic effects through reduction of serum cholesterol and triglyceride while increasing the levels of HDL-c. Consumption of plant sterol and their esters has also been reported to not only lower intestinal cholesterol absorption but decreased blood levels of the atherogenic LDL-c as well $[17,18]$. Since HDL possesses many features that contribute to the protection from atherosclerosis and related incidences [19], hypolipidemic agents with the ability to also increase serum levels of HDL-c are of great target.

The lower AI and CRI (Table 3) observed in this study in HFD-induced hyperlipidemic rats following the 15 days treatment with the triterpene suggested the cardiovascular protective potential of the compound. The formation of plaque in arteries, atherosclerosis, as a result of high cholesterol and LDL-c in the blood can lead to serious problems such as stroke, heart attack or even death [20]. Significant reduction in AI and CRI were also reported by Chaudhari et al. [12] using embelin extracted from Embelia ribes and this is considered beneficial in patients with atherosclerosis and obesity. The triterpenoid mixture from Protium heptaphyllum has also been reported to significantly reduce the AI in HFD-induced hyperlipidemia in rats [15]. It is apparent that the compound exerts its therapeutic effect through reduction of atherogenic cholesterol and triglyceride.

Prolonged consumption of high-fat diet increases synthesis of TG and inhibit $\beta$-oxidation of fatty acids which consequently leads to the accumulation of excess TG in the liver $[12,21]$. The accumulation of the TG causes an increase in liver weight and adipose tissues [12,22]. Interestingly, the triterpene from $P$. longifolia did not only reduce body weight, but liver weight and adiposity level (Table 2) in rats. The reduction in the liver enzymes activity (Table 4) and accumulation of fat droplets (Figure 3) in the liver of HFD-induced hyperlipidemic rats is indicative of the hepatoprotective effect of the triterpene with low cytotoxicity. Elevated liver enzymes

Table 4 Effect of the triterpene on liver enzymes on HFD-induced hyperlipidemia in rats

\begin{tabular}{llll}
\hline Group & ALP (U/L) & ALT (U/L) & AST (U/L) \\
\hline ND (after 21 days) & $73.00 \pm 24.85$ & $45.90 \pm 13.45$ & $226.00 \pm 95.57$ \\
(after 36 days) & $46.10 \pm 11.94$ & $51.90 \pm 10.32$ & $289.20 \pm 68.95$ \\
HFD (after 21 days) & $179.90 \pm 34.38$ & $78.20 \pm 30.09$ & $339.30 \pm 138.06$ \\
(after 36 days) & $249.00 \pm 60.40^{* *}$ & $83.80 \pm 18.67$ & $298.80 \pm 55.34$ \\
HFD/KEM $(100 \mathrm{mg} / \mathrm{kg})$ & $181.10 \pm 25.53$ & $42.30 \pm 6.90$ & $161.90 \pm 52.22$ \\
HFD/KEM $(200 \mathrm{mg} / \mathrm{kg})$ & $363.30 \pm 53.23$ & $48.80 \pm 8.28$ & $205.50 \pm 37.12$ \\
HFD/lovastatin $(10 \mathrm{mg} / \mathrm{kg})$ & $108.80 \pm 35.03$ & $44.11 \pm 9.82$ & $188.80 \pm 52.76$ \\
\hline
\end{tabular}



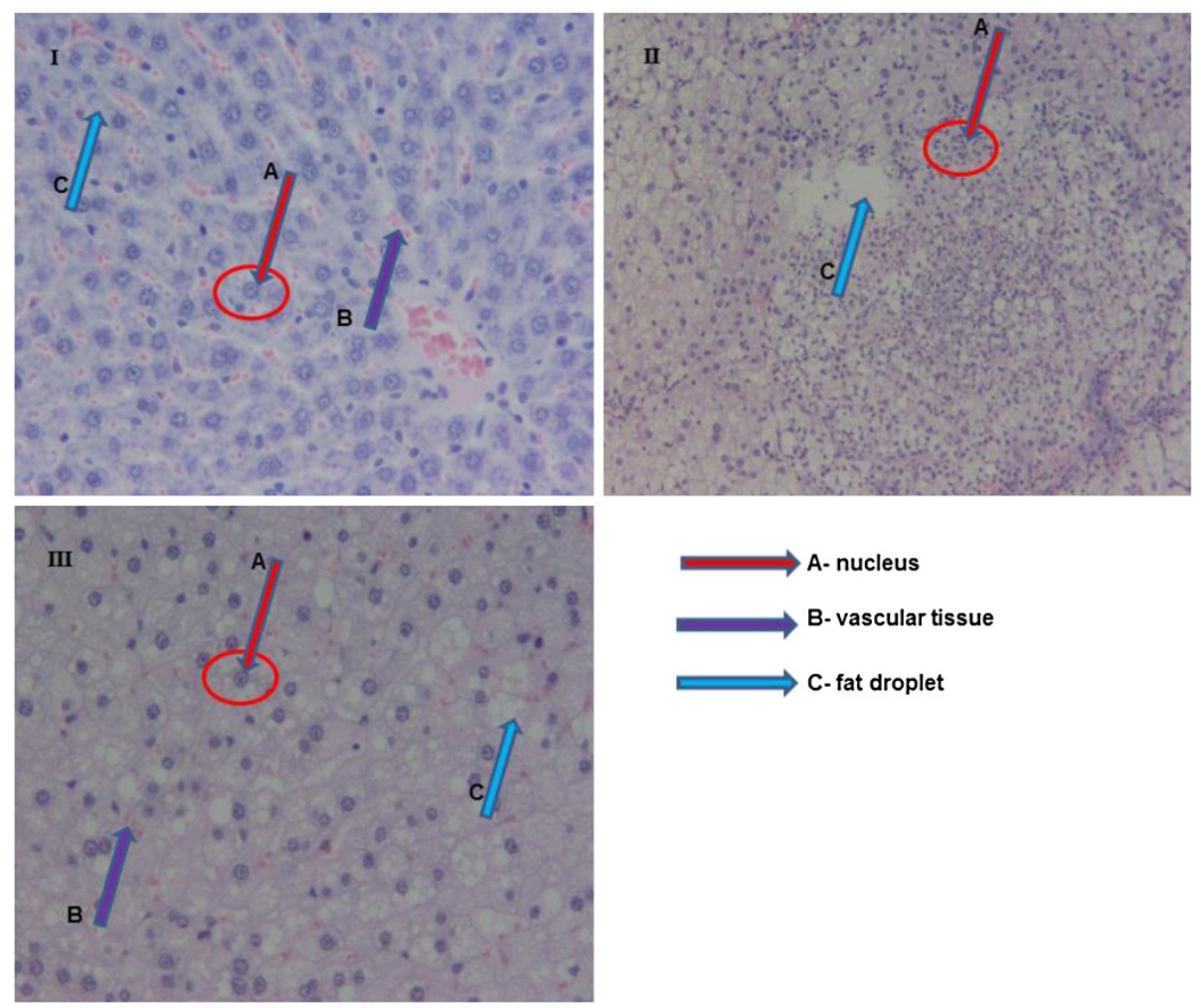

Figure 3 Histopathological changes (200x magnification) in liver of high fat diet induced hyperlipidemia after 15 days treatment with the triterpene. I- liver tissue of the rat fed a normal diet; II- liver tissue of the rat fed a HFD; III- liver tissue of the triterpene (200 mg/kg.bw) treated and HFD fed rat.

may indicate inflammation or damage to cells in the liver [23]. Thus liver enzymes are the proper indicator of normal function of the liver. A low cytotoxicity of the triterpenes from P. longifolia on hepatic and kidney cells has been reported [11].

\section{Conclusion}

The results obtained in this study show that the triterpene (methyl-3ß-hydroxylanosta-9,24-dien-21-oate) isolated from Protorhus longifolia has a significant hypolipidemic activity in high fat diet fed rats. This is evidenced by the reduction of serum TC and LDL-c, with an increased HDL-c concentration in the HFD fed treated groups. Significant reduction in AI and CRI by the triterpene was observed and it can thus be considered beneficial in reducing the risk of atherosclerosis. The compound could effectively control the amount of serum lipids and liver enzymes with lower toxicity. It is apparent that the compound could contribute to new formulation with significant hypolipidemic effects.

\section{Methods}

\section{Plant material}

Fresh stem barks of Protorhus longifolia (Benrh.) Engl. were collected in March 2012 from Hlabisa, Kwa-Zulu
Natal, South Africa. The plant (voucher specimen number RA01UZ) was authenticated by Dr. N.R. Ntuli, Department of Botany, University of Zululand. The plant material was thoroughly washed with tap water and then air dried. The air dried plant material was ground into powder ( $2 \mathrm{~mm}$ mesh) and stored in sterile brown bottles until use.

\section{Extraction and isolation}

The method of extraction and isolation of the triterpenes from the stem bark of $P$. longifolia has been previously described [11]. Briefly, the powdered plant material was first defatted with $n$-hexane and then extracted $(1: 5 \mathrm{w} / \mathrm{v})$ with chloroform. The compounds were isolated from the chloroform extract (13 g) using silica gel column chromatography $(24 \times 700 \mathrm{~mm}$; Silica gel $60 ; 0.063-0.2 \mathrm{~mm}$; 70-230 mesh ASTM, Merck, Darmstadt, Germany). The column was eluted stepwise with a mixture of $n$ hexane and ethyl acetate (9:1-3:7) and $20 \mathrm{ml}$ fractions were serially collected. Thin layer chromatography (TLC) (silica gel 60 TLC aluminium sheets $20 \mathrm{~cm} \times$ $20 \mathrm{~cm}, \mathrm{~F}_{254}$, Darmstadt, Germany) was used to analyse the fractions. The combined fraction 14 was further purified in ethyl acetate to afford the compound (KE1, $1.15 \mathrm{~g})$. Melting point of the compound was determined 
using Stuart SMP 11 melting point apparatus (Shalom Instruments supplies, Durban, South Africa). Spectroscopic data analysis, NMR $\left({ }^{1} \mathrm{H}-{ }^{1} \mathrm{H},{ }^{13} \mathrm{C}-{ }^{13} \mathrm{C}\right.$, in DMSO, Bruker $600 \mathrm{MHz}$ ), HRMS (in DCM, Waters Synapt G2) and infrared (IR) (Perkin-Elmer 100 FTIR) techniques were used to establish and confirm structure. Chemical shifts were expressed in $\delta$ (ppm).

\section{Animals}

This study was approved by University of Zululand Research Animal Ethics Committee (UZREC 171110030 Dept. 2013/23). Sprague-Dawley rats (180-220 g) were collected from animal house in the Department of Biochemistry, University of Zululand, South Africa. Experimental procedures were conducted following the guideline for care and supervision of experiments on animals. The animals were housed in standard cages and maintained at room temperature with 12:12-h light: dark cycle. All rats had free access to drinking water and standard rat feed in the experimental environment, for 1 week, before the experiment was conducted. Once the animals had adapted to the environment, forty-two (42) rats were divided into two groups; normal group (ND) consisting of 12 rats and the high fat diet (HFD) group consisting of 30 rats. After 21 days on their respective diets, 6 rats per group were sacrificed and the remaining rats of the HFD group were randomly divided into a total of four (4) groups of six rats per group.

\section{Experimental design}

1) Group 1: normal diet and vehicle throughout the study

2) Group 2: high fat diet and vehicle throughout the study

3) Group 3: was subdivided into two groups (A, B) and received high fat diet and compound (100 and $200 \mathrm{mg} / \mathrm{kg}$ body weight, respectively), dissolved in $2 \%$ Tween 20

4) Group 4: high fat diet and lovastatin $(10 \mathrm{mg} / \mathrm{kg}$ body weight), dissolved in $2 \%$ Tween 20

\section{Induction of dyslipidemia in rats}

The method previously described by Hor et al. [6] was followed to evaluate the anti-hyperlipidemic activity of the triterpene. Rats were made hyperlipidemia by feeding a high fat diet [commercial rat chow (97.3\%), Sunflower oil (15\%), bile salt $(0.5 \%)$, cholesterol (5\%), Thirmecil $(0.2 \%)]$. This HFD preparation was pelleted (about $3 \mathrm{~g}$ each) and fed daily to the rats for 36 days to induce hyperlipidemia.

\section{Measurement of body weight and food intake}

Body weight and food intake were recorded every other day over the study period of 21 or 36 days. Percentage weight change, food conversion (FC), and food efficiency ratio (FER) were then calculated.

$$
\begin{aligned}
& \% \text { weight change on day } 21 \text { or } 36 \\
& =\frac{\text { bodywtonday } 21 \text { or } 36-\text { body wtonday } 1}{\text { bodywtonday } 1} \times 100
\end{aligned}
$$

$$
\begin{aligned}
& \text { Food conversion }(\mathrm{FC})=\frac{\text { Foodintake }(g)}{w t \cdot g a i n(g)} \\
& \text { Food efficiency ratio(FER })=\frac{w t \cdot \operatorname{gain}(g)}{\operatorname{Foodintake}(g)}
\end{aligned}
$$

Relative liver weight per $100 \mathrm{~g}$ body weight of rat

$$
=\frac{\text { wt of rat liver }(g)}{\text { bodywt.onday } 21 \text { or } 36} \times 100
$$

where wt- weight

\section{Collection of blood samples and Liver for Lipid profile determination}

At the end of the experimental periods, the rats were fasted for 8 hours, and then sacrificed by a blow to the head and blood samples were collected by cardiac puncture. The collected blood samples were centrifuged at $3500 \mathrm{rpm}$ for 10 minutes and the serum collected for biochemical studies. The liver was excised, weighed and stored in formalin for histological studies.

Histology studies were carried out at the Vet Diagnostix Laboratories (Pietermaritzburg, SA) by qualified pathologist having no prior knowledge to which group they belonged. The liver tissues were stained with haematoxylin and eosin (H \& E). This method allowed for unbiased description of the histological lesions which were present or absent in the samples.

\section{Biochemical assays}

The serum samples were used for the estimation of total cholesterol (TC), total triglyceride (TG), HDL-cholesterol (HDL-c), AST, ALT and Alkaline phosphatase. Analysis was done using the Cobas c 111 analyzer.

LDL-cholesterol (LDL-c) was estimated using Friedwald's equation [24]

LDL-c $=[$ TC-(HDL-c $+($ TG/5) $]$

Other lipids parameters such as VLDL- cholesterol, coronary risk index and atherogenic index (AI) were calculated [12] as follows:

LDL-c $=[$ TC- $($ HDL-c $+(T G / 5)]$

VLDL-c $=[$ TG $-($ HDL-c + LDL-C $)]$ 
Atherogenic index $(\mathrm{AI})=\mathrm{LDL}-\mathrm{c} / \mathrm{HDL}-\mathrm{c}(\mathrm{mg} / \mathrm{dl})$ Coronary risk index $(\mathrm{CRI})=\mathrm{TC} / \mathrm{HDL}-\mathrm{c}(\mathrm{mg} / \mathrm{dl})$

$$
\text { Adiposity level }=\left[\sqrt[3]{\frac{\text { Body wt }(g)}{\text { naso-anal length }(\mathrm{mm})}}\right] \times 10^{4}
$$

\section{Statistical analysis}

Data was analyzed using one-way analysis of variance (ANOVA) followed my Tukey-Kramer multiple comparison test using GraphPad InStat ${ }^{\circ}$ version 3. The results are presented as mean \pm standard error of the mean (SEM). Values of $\mathrm{p}<0.05$ were considered significant.

\section{Additional file}

Additional file 1: A1 Spectra of KE1. Figure S1. IR spectrum of KE1.

Figure S2. ${ }^{1} \mathrm{H}-\mathrm{NMR}$ spectrum of KE1. Figure S3. ${ }^{13} \mathrm{C}$-NMR spectrum of KE1.

\section{Abbreviations}

Al: Atherogenic index; ANOVA: One-way analysis of variance; CRI: Coronary risk index: CVD: Cardiovascular diseases; FC: Food conversion; FER: Food efficiency ratio; HDL: High density lipoproteins; HFD: High fat diet; IR: Infrared; LDL: Low density lipoproteins; HRMS: High resolution mass spectrometry; ND: Normal group; NMR: Nuclear magnetic resonance; TG: Triacylglycerol; TLC: Thin layer chromatography; VLDL: Very low density lipoprotein; ALT: Alanine aminotransferase; AST: Aspartate aminotransferase.

\section{Competing interests}

Authors declare no competing interest.

\section{Authors' contributions}

KEM, SZZC performed the animal experiment; RAM, LAO contributed to compound isolation, identification and writing of the manuscript, TGD contributed in statistical analysis and editing of the work, ARO designed and coordinated the study. All authors read and approved the final manuscript.

\section{Acknowledgements}

This research was supported by the MRC of South Africa, and the University of Zululand Research Committee.

\section{Author details}

'Department of Biochemistry and Microbiology, University of Zululand, Private Bag X1001, KwaDlangezwa 3886, Republic of South Africa. ${ }^{2}$ Natural Products Research Unit, Lagos State University, Ojo, Lagos, Nigeria.

Received: 20 May 2014 Accepted: 6 August 2014

Published: 15 August 2014

\section{References}

1. Thayyil AH, Surulivel MKM, Ahmed MF, Ahamed GSS, Sidheeq A, Rasheed A, Ibrahim M: Hypolipidemic activity of Luffa Aegiptiaca fruits in cholesterol fed hypercholesterolemic rabbits. Int J Pharm App/ 2011, 2(1):81-88.

2. Jacobson TA, Miller M, Schaefer EJ: Hypertriglyceridemia and cardiovascular risk reduction. Clin Ther 2007, 29(5):763-77.

3. Adisakwattana S, Moonrat J, Srichairat S, Chanasit C, Tirapongporn H, Chanathong B, Ngamukote S, Mäkynen K, Sapwarobol S: Lipid-Lowering mechanisms of grape seed extract (Vitisvinifera $\mathrm{L}$ ) and its antihyperlipidemic activity. J Med Plant Res 2010, 4:2113-2120.

4. Stancu C, Sima S: Statins: mechanism of action and effects. J Cell Mol Med 2001, 5:378-387.

5. Thompson PD, Clarkson P, Karas RH: Statin associated myopathy. J Am Med Assoc 2003, 289:1681-1690.

6. Hor S, Farsi YE, Yam MF, Nuyah NM, Asmawi MZ: Lipid-lowering effects of Coriolus versicolor extract in poloxamer 407-induced hypercholesterolaemic rats and high cholesterol-fed rats. J Med Plants Res 2011, 5:2261-2266

7. Zhang X, Wu C, Wu H, Sheng L, Su Y, Zhang X, Luan H, Sun G, Sun X, Tian $Y$, Ji Y, Guo P, Xu X: Anti-hyperlipidemic effects and potential mechanisms of action of the caffeoylquinic acid-rich Pandanus tectorius fruit extract in hamsters fed a high fat-diet. PLoS One 2013, 8:e61922. doi:10.1371/journal.pone.0061922.

8. Ferreira EA, Gris EF, Rebello JM, Correia JF, de Oliveira LF, Filho DW, Pedrosa RC: The 2', $4^{\prime}, 6^{\prime}$-trihydroxyacetophenone isolated from Myrcia multiflora has antiobesity and mixed hypolipidemic effects with the reduction of lipid intestinal absorption. Planta Med 2011, 2011(77):1569-1574.

9. Suleiman MM, McGaw $\sqcup$, Naidoo V, Eloff JN: Detection of antimicrobial compounds by bioautography of different extracts of leaves of selected South African tree species. Afr J Tradit Complement Altern Med 2010, 7(1):64-68.

10. Mosa RA, Lazarus GG, Gwala PE, Oyedeji AO, Opoku AR: In vitro antiplatelet aggregation, antioxidant and cytotoxic activity of extracts of some Zulu medicinal plants. J Nat Prod 2011, 4:136-146.

11. Mosa RA, Oyedeji AO, Shode FO, Singh M, Opoku AR: Triterpenes from the stem bark of Protorhurs longifolia exhibit anti-platelet aggregation activity. Afr J Pharm Pharmacol 2011, 5:2698-2714.

12. Chaudhari HS, Bhandari U, Khanna G: Preventive effect of embelin from embelia ribes on lipid metabolism and oxidative stress in high-fat diet-induced obesity in rats. Planta Med 2012, 78(7):651-657.

13. Derosa G, Salvadeo S, Cicero AF: Prospects for the development of novel anti-hyperlipidemic drugs. Curr Opinion Invest Drugs 2006, 7:826-833.

14. Karalis DG, Ahedor VB, Liu L: Use of lipid-lowering medications and the likelihood of achieving optimal LDL-cholesterol goals in coronary artery disease patients. Cholesterol 2012. doi:10.1155/2012/861924.

15. Santos FA, Frota JT, Arruda BR, de Melo TS, da Silva AA, Brito GA, Chaves $\mathrm{MH}$, Rao VS: Antihyperglycemic and hypolipidemic effects of $\alpha, \beta$-amyrin, a triterpenoid mixture from Protium heptaphyllum in mice. Lipids Health Dis 2012, 11:98. doi:10.1186/1476-511X-11-98.

16. Gutierrez RMP: Evaluation of the hypoglycemic and hypolipidemic effects of triterpenoids from Prosthechea michuacana in STZ-induced type 2 diabetes in mice. Pharmacologia 2013. doi:10.5567/pharmacologia.2013.170.179.

17. Sudhahar V, Kumar SA, Sudharsan PT, Varalakshmi P: Protective effect of lupeol and its ester on cardiac abnormalities in experimental hypercholesterolemia. Vasc Pharmacol 2007, 46:412-418.

18. Brown AW, Hang J, Dussault PH, Carr TP: Plant sterol and stanol substrate specificity of pancreatic cholesterol esterase. J Nutr Biochem 2010, 21:736-740.

19. Benjamin J, Ansell KE, Watson AM, Fogelman MN, Gregg CF: High-density lipoprotein function. J Am College of Cardiol 2005, 46:1792-1798.

20. Jasmin L: Plaque Buildup In Arteries. In A.D.A.M. Medical Encyclopedia; 2012. http://www.nlm.nih.gov/medlineplus/ency/imagepages/19314.htm.

21. Luo Y, Li G, Li G, Yan J, Yi J, Zhang G: Discovery and identification of 2-phenylethyl 2, 6-dihydroxybenzoate as a natural lipid-lowering lead. Plant med 2011, 77(18):2047-2049.

22. Brenesel MD, Popović T, Pilija V, Arsić A, Milić M, Kojić D, Jojić N, Milić N: Hypolipidemic and antioxidant effects of buckwheat leaf and flower mixture in hyperlipidemic rats. Bosn J Basic Med Sci 2013, 13(2):100-108.

23. Imafidon KE, Okunrobo LO: Study on biochemical indices of liver function tests of albino rats supplemented with three sources of vegetable Oils. Nigerian Journal of Basic and Applied Science 2012, 19:105-110.

24. Friedewald WT, Levy RI, Fredrickson DS: Estimation of the concentration of low-density lipoprotein cholesterol in plasma, without use of the preparative ultracentrifuge. Clin 1972, 18:499-502.

doi:10.1186/1476-511X-13-131

Cite this article as: Machaba et al: In vivo anti-hyperlipidemic activity of the triterpene from the stem bark of Protorhus longifolia (Benrh) Engl. Lipids in Health and Disease 2014 13:131. 